\title{
Enhancing nitrogen availability from urea using clinoptilolite zeolite
}

\begin{abstract}
The high costs of nitrogen fertilizers have necessitated best-developed practices to optimize nitrogen fertilizers use whilst minimizing nitrate losses. Ammonium adsorption inhibits loss of nitrogen in the form of nitrate thereby increasing nitrogen availability for crops. Due to the negatively charged properties of nitrate, it moves freely in the soil solution and not adsorbed onto soil particle surfaces. In this study, clinoptilolite zeolite was used in soil leachingand ammonium adsorption and desorption studies to determine: (i) soil total nitrogen availability, exchangeable ammonium, and available nitrate, and (ii) the capacity of clinoptilolite zeolite to adsorb and desorb ammonium from different rates of urea. Different rates of urea amended with clinoptilolite zeolite significantly reduced ammonium and nitrate release from urea compared with urea alone. Clinoptilolite zeolite enhanced retention of soil total nitrogen, exchangeable ammonium, and available nitrate due to the high cation exchange capacity of the mineral to adsorb ammonium, thus, improving nitrogen availability through temporary retention on the exchange sites of the clinoptilolite zeolite. The availability of nitrogen can be enhanced if urea is amended with clinoptilolite zeolite.
\end{abstract}

Keyword: Adsorption; Ammonium; Clinoptilolite zeolite; Desorption; Nitrogen; Nitrate 